\title{
Experiences of using the Theoretical Domains Framework across diverse clinical environments: a qualitative study
}

\author{
Cameron J Phillips 1,2 \\ Andrea P Marshall ${ }^{3,4}$ \\ Nadia J Chaves ${ }^{5}$ \\ Stacey K Jankelowitz ${ }^{6,7}$ \\ Ivan B Lin ${ }^{8}$ \\ Clement T Loy 910 \\ Gwyneth Rees"l \\ Leanne Sakzewski ${ }^{12}$ \\ Susie Thomas ${ }^{13,14}$ \\ The-Phung To ${ }^{15}$ \\ Shelley A Wilkinson ${ }^{16,17}$ \\ Susan Michie ${ }^{18}$
}

'Division of Pharmacy, Flinders Medical Centre, Bedford Park, SA, Australia; ${ }^{2}$ School of Medicine, Flinders University, Adelaide, SA, Australia;

${ }^{3}$ Centre for Health Practice Innovation, Griffith Health Institute, Griffith University, Southport, QLD, Australia; ${ }^{4}$ Gold Coast University Hospital, Southport, QLD, Australia; ${ }^{5}$ Victorian Infectious Diseases Service, Royal Melbourne Hospital, Parkville, VIC, Australia; ${ }^{6}$ Central Clinical School, Sydney Medical School, University of Sydney, ${ }^{7}$ Institute of Neurosciences, Royal Prince Alfred Hospital, Sydney, NSW, Australia; ${ }^{8}$ Western Australian Centre for Rural Health, University of Western Australia, Geraldton, WA, Australia; 'School of Public Health, Sydney Medical School, University of Sydney, Sydney, NSW, Australia;

${ }^{10} \mathrm{H}$ untington Diseases Centre, Westmead Hospital, Westmead, NSW, Australia; "Centre for Eye Research Australia, University of Melbourne, Royal Victorian Eye and Ear Hospital, Melbourne, VIC, Australia; ${ }^{2}$ Queensland Cerebral Palsy and Rehabilitation Research Centre, University of Queensland, Brisbane, QLD, Australia; ${ }^{13}$ Physiotherapy Department, Flinders Medical Centre, Bedford Park, SA, Australia; ${ }^{14}$ International Centre for Allied Health Evidence (iCAHE), School of Health Sciences, University of South Australia, Adelaide, SA, Australia; ${ }^{15}$ Pharmacy Department, Austin Health, Heidelberg, VIC, Australia; ${ }^{16}$ Mater Research Institute, The University of Queensland, South Brisbane, QLD, Australia; ${ }^{17}$ Department of Nutrition and Dietetics, Mater Health Services, South Brisbane, QLD, Australia; ${ }^{18}$ University College London Centre for Behaviour Change, Department of Clinical, Educational and Health Psychology, University College, London, UK

Correspondence: Shelley A Wilkinson Department of Nutrition and Dietetics, Level 3 Salmon Building, Mater Health Services, Raymond Terrace, South Brisbane, QLD 4I0I, Australia

Tel +61731636000

Fax +61731632442

Email shelley.wilkinson@mater.org.au
This article was published in the following Dove Press journal:

Journal of Multidisciplinary Healthcare

18 March 2015

Number of times this article has been viewed

Background: The Theoretical Domains Framework (TDF) is an integrative framework developed from a synthesis of psychological theories as a vehicle to help apply theoretical approaches to interventions aimed at behavior change.

Purpose: This study explores experiences of TDF use by professionals from multiple disciplines across diverse clinical settings.

Methods: Mixed methods were used to examine experiences, attitudes, and perspectives of health professionals in using the TDF in health care implementation projects. Individual interviews were conducted with ten health care professionals from six disciplines who used the TDF in implementation projects. Deductive content and thematic analysis were used.

Results: Three main themes and associated subthemes were identified including: 1) reasons for use of the TDF (increased confidence, broader perspective, and theoretical underpinnings); 2) challenges using the TDF (time and resources, operationalization of the TDF) and; 3 ) future use of the TDF.

Conclusion: The TDF provided a useful, flexible framework for a diverse group of health professionals working across different clinical settings for the assessment of barriers and targeting resources to influence behavior change for implementation projects. The development of practical tools and training or support is likely to aid the utility of TDF.

Keywords: barriers and enablers, behavioral change, evidence-based practice, implementation, health care, Theoretical Domains Framework

\section{Introduction}

Implementation science promotes the systematic uptake of research findings into clinical practice with the aim of improving patient care and health care outcomes. Implementation of evidence-based practice requires behavior change, but changing behavior is difficult. ${ }^{1,2}$ Attempts at implementing evidence-based interventions that are tailored to the particular context have yielded mixed results. ${ }^{3}$ A number of factors can influence the uptake of an evidence-based intervention, and the success of implementation efforts depends on a careful assessment of barriers to and enablers of the behavior to be changed. A theory-based assessment allows for the systematic identification of such factors, can guide implementation and evaluation design, ${ }^{4}$ and may provide the basis for a better understanding of behavior change processes. ${ }^{5-7}$ There are a multitude of theoretical models which explain various behaviors, ${ }^{8}$ however, these are often difficult to access and understand by health professionals who do not have a psychology background. ${ }^{9}$

An integrative framework, the Theoretical Domains Framework (TDF), ${ }^{10}$ has been designed as a vehicle to help apply theoretic approaches to interventions aimed 
at behavioral change. ${ }^{11,12}$ The TDF was developed through an expert consensus process, including factor analysis and validation to identify psychological and organizational theory relevant to health practitioner clinical behavior change. ${ }^{10}$ Following further refinement, it now comprises of 14 domains and 84 constructs that allows synthesis of a multitude of coherent behavior change theories into a single framework that allows assessment and explanation of behavioral problems and associated barriers and enablers, and inform the design of appropriately targeted interventions. ${ }^{11,13}$ The TDF domains and their descriptors are outlined in Table 1; the 14 domains are 1) knowledge, 2) skills, 3) social/professional role and identity, 4) beliefs about capabilities, 5) optimism, 6) beliefs about consequences, 7) reinforcement, 8) intentions, 9) goals, 10) memory, attention, and decision processes,

Table I The domains of the Theoretical Domains Framework (TDF)

\begin{tabular}{|c|c|}
\hline TDF domain & Description \\
\hline Knowledge & An awareness of the existence of something \\
\hline Skills & $\begin{array}{l}\text { An ability or proficiency acquired through } \\
\text { practice }\end{array}$ \\
\hline $\begin{array}{l}\text { Social/professional } \\
\text { role and identity }\end{array}$ & $\begin{array}{l}\text { A coherent set of behaviors and displayed } \\
\text { personal qualities of an individual in a social } \\
\text { or work setting }\end{array}$ \\
\hline $\begin{array}{l}\text { Beliefs about } \\
\text { capabilities }\end{array}$ & $\begin{array}{l}\text { Acceptance of the truth, reality, or validity } \\
\text { about an ability, talent, or facility that a person } \\
\text { can put to constructive use }\end{array}$ \\
\hline Optimism & $\begin{array}{l}\text { The confidence that things will happen for the } \\
\text { best, or that desired goals will be attained }\end{array}$ \\
\hline $\begin{array}{l}\text { Beliefs about } \\
\text { consequences }\end{array}$ & $\begin{array}{l}\text { Acceptance of the truth, reality, or validity about } \\
\text { outcomes of a behavior in a given situation }\end{array}$ \\
\hline Reinforcement & $\begin{array}{l}\text { Increasing the probability of a response } \\
\text { by arranging a dependent relationship, or } \\
\text { contingency, between the response and } \\
\text { a given stimulus }\end{array}$ \\
\hline Intentions & $\begin{array}{l}\text { A conscious decision to perform a behavior } \\
\text { or a resolve to act in a certain way }\end{array}$ \\
\hline Goals & $\begin{array}{l}\text { Mental representation of outcomes or end } \\
\text { states that an individual wants to achieve }\end{array}$ \\
\hline $\begin{array}{l}\text { Memory, attention } \\
\text { and decision processes }\end{array}$ & $\begin{array}{l}\text { The ability to retain information, focus } \\
\text { selectively on aspects of the environment, and } \\
\text { choose between two or more alternatives }\end{array}$ \\
\hline $\begin{array}{l}\text { Environmental context } \\
\text { and resources }\end{array}$ & $\begin{array}{l}\text { Any circumstance of a person's situation or } \\
\text { environment that discourages or encourages the } \\
\text { development of skills and abilities, independence, } \\
\text { social competence, and adaptive behavior }\end{array}$ \\
\hline Social influences & $\begin{array}{l}\text { Those interpersonal processes that can cause } \\
\text { an individual to change their thoughts, feelings, } \\
\text { or behaviors }\end{array}$ \\
\hline Emotion & $\begin{array}{l}\text { A complex reaction pattern, involving } \\
\text { experiential, behavioral, and physiological } \\
\text { elements, by which the individual attempts to } \\
\text { deal with a personally significant matter or event }\end{array}$ \\
\hline $\begin{array}{l}\text { Behavioral } \\
\text { regulation }\end{array}$ & $\begin{array}{l}\text { Anything aimed at managing or changing } \\
\text { objectively observed or measured actions }\end{array}$ \\
\hline
\end{tabular}

Note: Data from Cane et al."
11) environment context and resources, 12) social influences, 13) emotion, and 14) behavioral regulation. ${ }^{11}$

The TDF has been used prospectively to facilitate implementation of health care interventions ${ }^{14-16}$ and retrospectively in theory-based process evaluation. ${ }^{11,14,17}$ Most studies have relied on qualitative analyses of interview or focus group data, which are time consuming, although questionnaire measures of the TDF have recently been published. ${ }^{18-20}$ Evaluation of the use of the TDF in everyday practice by those implementing projects in the clinical environment is limited, therefore we aimed to explore the experiences of health care practitioners from various disciplines using the TDF. This included examining the perceived relevance and utility of the TDF domains in identifying barriers to evidence uptake and when designing implementation strategies to facilitate behavior change in a variety of clinical settings. We anticipated that insights from this cohort would be useful to clinicians or researchers using or contemplating using the TDF.

\section{Materials and methods Design}

Mixed methods were used to examine the experiences, attitudes, and perspectives of health professionals in understanding and use of the TDF in healthcare implementation projects.

\section{Participants}

Participants were health professionals from a variety of medical, nursing and allied health disciplines who were implementing healthcare improvement projects. Participants were identified from a cohort of Australian National Health and Medical Research Council (NHMRC) Translating Research into Practice (TRIP) Fellows (http://www. nhmrc.gov.au/grants/apply-funding/translating-researchpractice-trip-fellowships) who had received training on the TDF. Training consisted of a 1-day master class on theories and frameworks to assess barriers and enablers to evidence-based health service change, including an introduction to the TDF. Participants were recruited via the email distribution network of the 2012 NHMRC TRIP Fellows. All ten prospective participants who used the TDF in their implementation projects were invited and consented to participate in the study.

\section{Materials}

Interview questions were theoretically informed by the TDF and formulated by three researcher-participants 
(AM, CP, and GR). They were further refined after external review by one author (SM) and three experts on the TDF. Interview questions (available from authors on request) focused on the characteristics of participants, and their understanding and use of TDF in their project. A survey was developed based on the 14 domains of the TDF (available from authors on request) to evaluate perceived usefulness and relevance of each TDF domain to identify barriers in each participants' organization to inform implementation strategies to change clinical practice behavior. The participants were instructed to rate on a 7-point Likert scale (1 being least relevant and 7 the most relevant) the relevance and usefulness of the 14 theoretical domains to their individual health care projects.

\section{Procedure}

This study was approved by the Griffith University Human Research Ethics Committee (Southport, QLD, Australia: NRS/15/13/HREC). Informed consent was obtained prior to interview commencement. The questions and survey were sent to participants in June 2013 to allow them sufficient time to consider their responses prior to the interview. Respondents submitted survey responses via email. Telephone interviews were conducted by two authors (AM and NC) during July and August 2013. An interview guide was used to ensure consistency of data collection. The duration of each interview was approximately 45 minutes. No interviews were repeated. Interviews were recorded and transcribed verbatim.

\section{Analysis}

Demographic data collected in the telephone interview were summarized using descriptive statistics. Descriptive statistics were calculated to summarize frequency of responses about the relevance and usefulness of the 14 domains of the TDF. Distribution of responses was examined using histograms. Qualitative analysis involved the complementary methods of deductive content ${ }^{21}$ and thematic analysis. ${ }^{22}$ Deductive content analysis was led by $\mathrm{NC}$ and thematic analysis by AM, SW, and IL, each who individually identified then discussed broad themes within the data. Group discussion was then used to further refine the themes.

\section{Results}

Ten health professionals participated (Table 2). The mean age of participants was 40 years (32-43 years). Seven participants held higher research degrees at the doctoral level and three held Masters level qualifications or equivalent. Participants
Table 2 Participants characteristics and aims of implementation project

\begin{tabular}{|c|c|c|}
\hline Discipline & Aim of implementation project & Setting \\
\hline $\begin{array}{l}\text { Academic health } \\
\text { psychology }\end{array}$ & $\begin{array}{l}\text { Integrate psychosocial care into } \\
\text { low vision rehabilitation services }\end{array}$ & unity \\
\hline Dietetics & $\begin{array}{l}\text { Implement nutrition practice } \\
\text { guidelines for women with } \\
\text { gestational diabetes }\end{array}$ & $\begin{array}{l}\text { Tertiary } \\
\text { hospital }\end{array}$ \\
\hline Medical & $\begin{array}{l}\text { Reduce antipsychotic use } \\
\text { in patients with Huntington disease } \\
\text { in residential care }\end{array}$ & $\begin{array}{l}\text { Residential } \\
\text { care }\end{array}$ \\
\hline Medical & $\begin{array}{l}\text { Implement an antimicrobial } \\
\text { stewardship program in an } \\
\text { intensive care unit }\end{array}$ & $\begin{array}{l}\text { Tertiary } \\
\text { hospital }\end{array}$ \\
\hline Medical & $\begin{array}{l}\text { Improve the use of secondary } \\
\text { prevention medications after stroke }\end{array}$ & $\begin{array}{l}\text { Tertiary and } \\
\text { secondary } \\
\text { hospital }\end{array}$ \\
\hline $\begin{array}{l}\text { Occupational } \\
\text { therapy }\end{array}$ & $\begin{array}{l}\text { Increase intensive upper limb } \\
\text { training for children with hemiplegia }\end{array}$ & Community \\
\hline Pharmacy & $\begin{array}{l}\text { Improve vancomycin prescribing } \\
\text { and monitoring }\end{array}$ & $\begin{array}{l}\text { Tertiary } \\
\text { hospital }\end{array}$ \\
\hline Pharmacy & $\begin{array}{l}\text { Improve management } \\
\text { of medications when patients are } \\
\text { fasting or nil by mouth }\end{array}$ & $\begin{array}{l}\text { Tertiary } \\
\text { hospital }\end{array}$ \\
\hline Physiotherapy & $\begin{array}{l}\text { Implement self-management } \\
\text { approaches for lower back pain, } \\
\text { to educate health practitioner }\end{array}$ & Community \\
\hline Physiotherapy & $\begin{array}{l}\text { Implement guidelines to prevent } \\
\text { falls for patients after hip fracture }\end{array}$ & $\begin{array}{l}\text { Tertiary } \\
\text { hospital }\end{array}$ \\
\hline
\end{tabular}

were employed at tertiary hospitals $(\mathrm{n}=7 ; 70 \%)$, primary care $(n=2 ; 20 \%)$, or residential care services $(n=1 ; 10 \%)$. Health disciplines were diverse comprising medical specialists $(n=3)$, pharmacists $(n=2)$, physiotherapists $(n=2)$, psychology researcher $(n=1)$, dietitian $(n=1)$, and occupational therapist $(\mathrm{n}=1)$. Clinical practice areas included pediatrics, neurology, maternal health, aged care, quality use of medicines, infectious diseases, clinical education, and musculoskeletal health.

Seven participants used the TDF prospectively to inform their projects; three participants used the TDF retrospectively either to formally analyze data or to help understand challenges with implementation. There was little difference in how participants rated relevance and usefulness of individual TDF domains for their implementation projects, therefore only usefulness ratings are presented in Figure 1. The small sample size precluded further statistical testing but a number of domains (eg, knowledge and skills) show Likert scale ratings skewed toward the higher (more useful) range.

Thematic analysis of interview transcripts identified three main themes and associated subthemes including: 1) reasons for use of the TDF (increased confidence, broader 


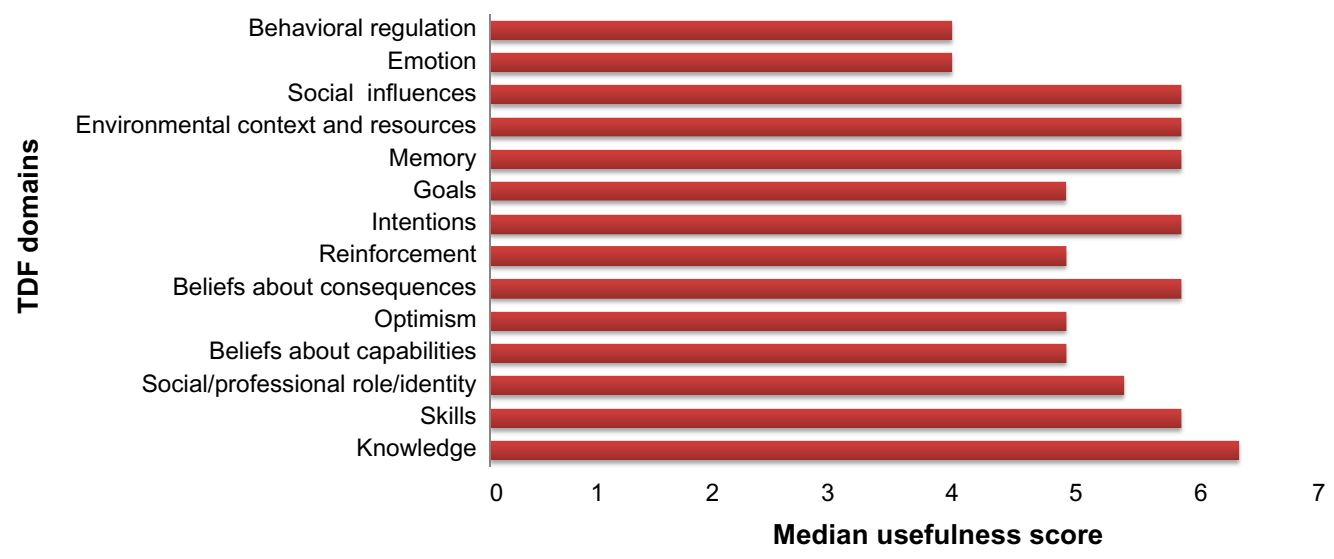

Figure I Median Likert score by TDF domain.

Abbreviation: TDF, Theoretical Domains Framework.

perspective, and theoretical underpinnings); 2) challenges using the TDF (time and resources, operationalization of the TDF); and 3) future use of the TDF.

\section{Theme I: reasons for use of the TDF}

Most participants were influenced to use the TDF following attendance at a master class that introduced the TDF; one participant (academic health psychologist; GR) had previous knowledge of and experience with using the TDF.

\section{Increased confidence}

Participants reported that their confidence in undertaking their projects increased when using the TDF. They reported using the TDF to ensure that unwarranted assumptions about barriers and enablers were not made and also used the TDF to double-check decisions already made. The TDF was used to ensure "all aspects of possible influences" were considered in specific projects and "to ensure that I captured the most significant barriers or enablers to implementation". For one participant this provided "confidence that I wasn't missing something in the process" something that was considered difficult "without using some kind of framework". Many of the participants described the TDF as a "systematic approach" to identifying barriers and enablers that then allowed the researcher "to make sure that the interventions ... put into place were appropriate".

\section{Broad perspective}

The use of the TDF to identify a wide variety of possible barriers and enablers to behavior change was seen as key to the development of targeted interventions that were likely to bring about change. With barriers and enablers systematically identified, participants were able to select and tailor interventions to the specific context in which they were working. This was considered a good strategy to "better identify where to invest ... time and resources".

\section{Theoretical underpinnings}

The theoretical underpinnings of the TDF were considered an important and often mentioned strength. While other theoretical approaches were considered by some participants, the fact that the TDF provided a synthesis of concepts from a number of psychological theories of behavior change was seen as particularly appealing because it meant that you did not have to try "to put a square peg in a round hole" and it helped by "broaden(ing) the understanding of the barriers of how to develop an intervention".

\section{Theme 2: challenges faced when using the TDF}

Although all participants acknowledged the benefits of using the TDF, they identified several challenges including time and resources issues, and steps in operationalization of the TDF.

\section{Time and resource issues}

The time taken and resources required to use the TDF were amongst the most frequent challenges described by participants. Almost all participants had used qualitative methods in their projects, thus associated interviewing, transcribing, and analyzing data were considered time consuming and resource intensive. Some used the TDF retrospectively (applied to previous data) and acknowledged the trade-off between rigor and feasibility with one participant commenting "... I would have loved to have used [the TDF] prospectively ... but I just didn't have the time to do that, 
so I used a retrospective approach". Using the retrospective approach (because of time restraints) was considered a limitation because there was a lack of certainty whether "I really covered all the domains and identified all possible influences". For another participant, using the TDF was considered time effective because it was believed that this approach would assist in streamlining the investment of time and resources required for implementation.

\section{Challenges to operationalization of the TDF}

Some participants described operationalization of the TDF as challenging because of a perceived lack of familiarity with the framework. There were considerable variations in the reported understanding of the framework. Developing a clear understanding of the domains and associated constructs for each domain was complicated by lack of clear operational definitions such that one participant commented that "the language is a bit different to what I'm used to ... It's just that some [constructs] I still don't really understand ... I don't have a strong conceptual understanding". The use of the TDF was also challenging because of perceived "overlap" between domains that resulted in repetition. For one participant it was as though the "huge overlap" made the domains "blend into each other" and made it hard to "tease out what I was trying to do".

Difficulty understanding the domains and associated constructs was reinforced by another participant who commented, “it wasn't exactly clear to me how the domains should be interpreted". The constructs that were listed gave me "... a bit more of an idea ..." however the perceived language complexity was considered "frustrating". The number of constructs within and across domains was also considered an issue with one participant describing this about being “... far too complicated ... and unwieldy" and another indicating being selective about what aspects of the TDF informed survey development because of the concern that using the TDF in its entirety would "... push the envelope ..." and be burdensome to the participants. One participant described interpretation of the domains and constructs as a subjective exercise that "... comes down to the interpretation of the TDF ..." that was influenced by "... what sort of lens you are looking [through]..."

As the TDF is informed in part by psychological theories, some participants felt disadvantaged by not having a background in psychology. One participant said it "took a little while to really get my head around it". Attempting to develop further understanding of the domains and constructs through reading literature did not always assist with a clearer understanding because "what [an author] interpreted as a particular domain was completely not what I'd interpreted as a particular domain". In contrast, the two participants with postgraduate qualifications in psychology did not articulate any specific challenges in understanding the domains or constructs within the TDF. For one, reading "... quite broadly around the TDF" helped to "... [understand] that each of the constructs fleshed out what was in the domain". However, the other acknowledged that "it's all a bit open to interpretation" although this wasn't viewed as problematic. It was suggested that an established and validated process to analyze the TDF would have been helpful during analysis because "it was difficult to code ...". Once coding was completed it was then challenging to determine which domains in the data were most important.

Unfamiliarity with psychological constructs meant that, for some participants, their collaborators or participant groups were hesitant in accepting the TDF framework for their implementation projects. For example, one participant's supervisor said, "I think that's going to be far too complicated for the (surgeons) - they'll get a bit scared ..." Another challenge in operationalization of the TDF related to uncertainties in how to apply the results to effect change. One participant commented, "... having the domains is really helpful, but I think there needs to be a better way to compare ... them". One participant made the observation that if you were using the TDF to explore individual behavior then you might overlook other important factors including "systems level" considerations (eg, cultural change and leadership) although acknowledged that the TDF might pick up these issues used to evaluate barriers and enablers at the organizational level.

Uncertainties with application of the TDF were also related to published studies that had very modest effects or failed to affect behavioral change despite being theoretically informed ${ }^{14,17}$ “... I just have to say that I'm a bit disheartened that even though something might be theory informed there's no guarantees that it is going to be translating to great impact or great success. That's the only thing because we recently read an article [...] it was a spectacular failure ... It was the exact same department, the exact same sort of method of rollout, and things like that".

Demonstrating the influence the TDF might have on the results of implementation projects was seen as challenging and although all participants believed that the TDF enhanced their ability to comprehensively identify possible barriers and enablers, the extent to which it positively influenced study outcomes was less certain. One participant commented, “I'm getting good results but with a multidimensional intervention it's hard to know if using the TDF to hone my intervention and dissemination, whether that is the result of the TDF. So the 
TDF, I think it's helped me to make some informed choices upstream and the results I'm getting downstream at this point look quite good but it'll be difficult to draw the association between good results and use of the TDF".

\section{Theme 3: thoughts on future use of the TDF}

All participants stated they would use the TDF in future projects and seven suggested strategies they felt could help in its future use. Two participants suggested developing an instrument through which the TDF constructs could be evaluated. A questionnaire was considered a way of quantifying the results of the TDF and could also "take some of the time burden away from using it, because it was incredibly time consuming". The disadvantage of restricting the TDF to a questionnaire was limiting the "richness of information that you would [get] using an ... interview approach". Others suggested development of resources to support use of the TDF (eg, formalized training, practical written guidelines).

\section{Discussion}

This study provides insight into how the TDF was operationalized, used, and experienced by health professionals to implement evidence-based changes in practice across a range of clinical settings. Our findings highlight that the TDF is considered a useful approach providing a systematic, comprehensive, and theory-derived process to identify barriers to clinical practice change that can help identify target behaviors for change and inform implementation strategies. However, even in this group of experienced health professionals who had received some training in the TDF, challenges remain regarding the comprehension and independence of domains, the feasibility of using such an in-depth procedure prospectively in clinical practice, and how best to use findings to direct implementation activities.

Our study found that the TDF was a flexible tool that could be used across different settings and in different ways to understand implementation issues and plan implementation activities. The TDF was used both prospectively and retrospectively using interview, observational, and survey data. All the domains proved to be relevant to understanding barriers across all contexts and could be applied to identify issues at the individual, team, or organizational level. These findings concur with a review of 50 qualitative studies exploring clinicians' perceptions and experiences of clinical quality improvement interventions, which found that all TDF domains were relevant and accounted for barriers and enablers to clinical practice change. Consistent with our findings, the TDF was flexible enough to be applied across clinical quality interventions and the authors proposed that it may form the basis for a model of clinical quality policy implementation. ${ }^{23}$

Our findings suggest that there is likely to be considerable variation in how researchers and practitioners interpret and use the TDF and highlight that if the TDF is to move significantly beyond the academic literature on implementation science toward a tool that can be routinely used in practice, more needs to be done to inform healthcare professionals of the domains and constructs. Even within our sample of professionals who had received tutorials on theories and frameworks to systematically inform interventions, confusion was still present. Some participants struggled with the complexity of the TDF language and the perceived lack of independence between the domains. These findings are not entirely new, as similar challenges have previously been reported. ${ }^{18,24,25}$ The resource intensive nature of using the TDF has been previously reported as a challenge in its use, although may be balanced with achievement of sustainable behavior change. ${ }^{26}$ Perhaps, this is not surprising given that the validation of the TDF was conducted via recruitment of eligible participants who possessed a good understanding of psychological theory. ${ }^{11}$ While our participants did receive limited training, most had no previous experience in utilizing theories or frameworks to guide implementation interventions. Some participants had already commenced their projects prior to the training on behavior change. Therefore it may be argued that the study cohort is more representative of health care professionals/researchers on-the-ground with limited or no behavior change theory experience and without the benefit of a behavior change expert on their project team. Previous authors have recommended that research teams include a health psychologist in order to utilize the $\mathrm{TDF}^{10}$ and many published studies on the TDF have one or more behavioral change experts as an author. ${ }^{14,15}$ Unfortunately, when dealing with implementation issues in practice this is often not the case with a lack of access, resourcing, and time as described in our study. Accessible training (eg, online) including tangible examples of the TDF domains across a variety of settings that can demonstrate subtle differences between constructs would be useful for healthcare professionals/researchers. Workshops have been conducted since March 2013 (subsequent to the current study) in the United Kingdom (http://yhahsn.org.uk/ improvement-academy/trainng-workshops/and http://www. ucl.ac.uk/behavior-change) to support use of the TDF.

One strength of our study was its reach across a range of clinical settings and health care professionals involved in 
the implementation of current evidence-based health care interventions. However, a number of limitations need to be acknowledged. Firstly, as a cohort of NHMRC TRIP Fellows, the authors of this paper were the designers of the study, the interview guide, and participants. Furthermore, participants were interviewed by their peers. Interview responses (and the delivery of interview questions), therefore, may have been more strongly influenced by social desirability bias and confirmation bias than if the participant was completely independent from the research process. Secondly, our interview did not probe deeply into beneficial aspects of the TDF. Whilst most participants reported that the TDF was useful and they would use it again, the reasons for this were not fully elucidated. Thirdly, it was not possible in this study to determine in detail, exactly which domains were considered (accepted or rejected) and how the TDF directly influenced implementation strategies and the process by which participants linked domains of the TDF to target behaviors for change. It was also not possible to identify specifically which domains were considered to be overlapping or confusing. This is an important area for future research to explore in order to improve the utility of the TDF for researchers and health care practitioners more widely. Finally, this study was conducted prior to the participants having completed their implementation projects. So while the findings provide us with some insight into how useful the TDF was in assisting health professionals to design implementation projects, it is not possible to comment on the overall success of the projects that utilized the TDF.

Our study demonstrated that the TDF is a useful, flexible framework for health professionals managing implementation that assists by providing a structured framework for the assessment of barriers and enablers and targeting of resources to influence behavioral change. The TDF is appropriate to be used by a variety of healthcare disciplines, across a range of clinical settings, and to aid in the development of implementation projects. To overcome the challenges regarding comprehension of the TDF, as well as to enhance the feasibility of using such an in-depth procedure prospectively in clinical practice, practical tools, and training or support is likely to aid the utility of TDF so it can be used most effectively by health care professionals and researchers on-the-ground in the design and implementation of health care projects.

\section{Acknowledgments}

The following authors were funded by an Australian National Health and Medical Research Council Translating Research into Practice Fellowship over the duration of this work: CJP,
1035960; APM, 1033392; NJC, 1018810; SKJ, 1030162; IL, 1035152; CTL, 1035429; GR, 1018809; LS, 1036183; ST, 1035256; TPT, 1035729; SAW, 1031632. The authors would like to thank Janet Curran (Ottawa Hospital Research Institute, Canada), Denise O'Connor (Monash University, Australia), and Simon French (University of Melbourne, Australia) for their critical review of our interview questions.

\section{Author contributions}

All authors were involved in the concept and design of this study. Interview questions were developed by APM, CJP, and GR. Interviews were conducted by APM and NJC and analysis was performed by APM, SAW, IL, and NJC. Statistics were performed by CTL. All authors contributed to the writing of the manuscript and read and approved the final version.

\section{Disclosure}

The authors report no conflicts of interest in this work.

\section{References}

1. Grol R, Grimshaw J. From best evidence to best practice: effective implementation of change in patients' care. Lancet. 2003;362(9391): 1225-1230.

2. Abraham C, Kelly MP, West R, Michie S. The UK national institute for health and clinical excellence public health guidance on behaviour change: a brief introduction. Psychol Health Med. 2009;14(1):1-8.

3. Grimshaw JM, Thomas RE, MacLennan G, et al. Effectiveness and efficiency of guideline dissemination and implementation strategies. Health Technol Assess. 2004;8(6):1-72.

4. French SD, Green SE, O'Connor DA, et al. Developing theory-informed behaviour change interventions to implement evidence into practice: a systematic approach using the theoretical domains framework. Implement Sci. 2012;7:38.

5. Albarracin D, Gillette JC, Earl AN, Glasman LR, Durantini MR, Ho MH. A test of major assumptions about behavior change: a comprehensive look at the effects of passive and active HIV-prevention interventions since the beginning of the epidemic. Psychol Bull. 2005;131(6): 856-897.

6. Noar SM, Zimmerman RS. Health behavior theory and cumulative knowledge regarding health behaviors: are we moving in the right direction? Health Edu Res. 2005;20(3):275-290.

7. Michie S, Prestwich A. Are interventions theory-based? Development of a theory coding scheme. Health Psychol. 2010;29(1):1-8.

8. Michie S, West K, Campbell R, Brown J, Gainforth H. An ABC of Behaviour Change Theories. London, UK: Silverback Publishing; 2014.

9. Michie S, Johnston M, Abraham C, et al. Making psychological theory useful for implementing evidence based practice: a consensus approach. Qual Saf Health Care. 2005;14(1):26-33.

10. Francis JJ, O'Connor D, Curran J. Theories of behaviour change synthesised into a set of theoretical groupings: introducing a thematic series on the theoretical domains framework. Implement Sci. 2012;7:24.

11. Cane J, O'Connor D, Michie S. Validation of the theoretical domains framework for use in behaviour change and implementation research. Implement Sci. 2012;7:37.

12. Duncan EM, Francis JJ, Johnston M, et al. Learning curves, taking instructions, and patient safety: using a theoretical domains framework in an interview study to investigate prescribing errors among trainee doctors. Implement Sci. 2012;7:86. 
13. Michie S, Atkins L, West R. The Behaviour Change Wheel: A Guide to Designing Interventions. London, UK: Silverback Publishing; 2014.

14. French SD, McKenzie JE, O'Connor DA, et al. Evaluation of a theoryinformed implementation intervention for the management of acute low back pain in general medical practice: the IMPLEMENT cluster randomised trial. PLoS One. 2013;8(6):e65471.

15. Tavender EJ, Bosch M, Gruen RL, et al. Understanding practice: the factors that influence management of mild traumatic brain injury in the emergency department - a qualitative study using the Theoretical Domains Framework. Implement Sci. 2014;9:8.

16. Dyson J, Lawton R, Jackson C, Cheater F. Development of a theorybased instrument to identify barriers and levers to best hand hygiene practice among healthcare practitioners. Implement Sci. 2013;8:111.

17. Curran JA, Brehaut J, Patey AM, Osmond M, Stiell I, Grimshaw JM. Understanding the Canadian adult CT head rule trial: use of the theoretical domains framework for process evaluation. Implement Sci. 2013;8:25.

18. Taylor N, Parveen S, Robins V, Slater B, Lawton R. Development and initial validation of the Influences on Patient Safety Behaviours Questionnaire. Implement Sci. 2013;8:81.

19. Huijg JM, Gebhardt WA, Dusseldorp E, et al. Measuring determinants of implementation behavior: psychometric properties of a questionnaire based on the theoretical domains framework. Implement Sci. $2014 ; 9: 33$
20. Taylor N, Lawton R, Conner M. Development and initial validation of the determinants of physical activity questionnaire. Int $J$ Behav Nutr Phys Act. 2013;10:74.

21. Elo $\mathrm{S}$, Kyngas $\mathrm{H}$. The qualitative content analysis process. $J A d v$ Nurs. 2008;62(1):107-115.

22. Fereday J, Muir-Cochrane E. Demonstrating rigor using thematic analysis: a hybrid approach of inductive and deductive coding and theme development. Int J Qual Methods. 2006;5(1):80-92.

23. Lipworth W, Taylor N, Braithwaite J. Can the theoretical domains framework account for the implementation of clinical quality interventions? BMC Health Serv Res. 2013;13:530.

24. Bussieres AE, Patey AM, Francis JJ, Sales AE, Grimshaw JM; Canada Prime Plus Team. Identifying factors likely to influence compliance with diagnostic imaging guideline recommendations for spine disorders among chiropractors in North America: a focus group study using the Theoretical Domains Framework. Implement Sci. 2012;7:82.

25. Beenstock J, Sniehotta FF, White M, Bell R, Milne EM, AraujoSoares $\mathrm{V}$. What helps and hinders midwives in engaging with pregnant women about stopping smoking? A cross-sectional survey of perceived implementation difficulties among midwives in the North East of England. Implement Sci. 2012;7:36.

26. Taylor N, Lawton R, Slater B, Foy R. The demonstration of a theorybased approach to the design of localized patient safety interventions. Implement Sci. 2013;8:123.
Journal of Multidisciplinary Healthcare

\section{Publish your work in this journal}

The Journal of Multidisciplinary Healthcare is an international, peerreviewed open-access journal that aims to represent and publish research in healthcare areas delivered by practitioners of different disciplines. This includes studies and reviews conducted by multidisciplinary teams as well as research which evaluates the results or conduct of such teams or

\section{Dovepress}

healthcare processes in general. The journal covers a wide range of areas and welcomes submissions from practitioners at all levels, from all over the world. The manuscript management system is completely online and includes a very quick and fair peer-review system. Visit http://www.dovepress.com/testimonials.php to read real quotes from published authors. 